\title{
Development and Validation of High-Performance Liquid Chromatographic Method for Quantification of Irinotecan and Its Active Metabolite SN-38 in Colon Tumor Bearing NOD/SCID Mice Plasma Samples: Application to Pharmacokinetic Study
}

\author{
Neetika Taneja ${ }^{1}$, Vikram Gota ${ }^{2}$, Murari Gurjar ${ }^{2}$ and Kamalinder K. Singh ${ }^{3 *}$ \\ ${ }^{I}$ C. U. Shah College of Pharmacy, S.N. D. T. Women's University, Santacruz (W), Mumbai 400049, India \\ ${ }^{2}$ Department of Clinical Pharmacology, Advanced Centre for Treatment, Research and Education in Cancer, Navi Mumbai, India \\ ${ }^{3}$ School of Pharmacy and Biomedical Sciences, University of Central Lancashire, Preston, PR1 2HE, United Kingdom
}

Received: 05 September 2017; accepted: 05 February 2018

\begin{abstract}
Irinotecan (IRT) is an antineoplastic agent widely used in the treatment of various cancers primarily in colorectal cancer. A new, simple and sensitive high-performance liquid chromatography (HPLC) method coupled with fluorescence detector was developed and validated to quantify IRT and its active metabolite SN38 in the plasma of non-obese diabetic/severe combined immune-deficient mice (NOD/SCID) mice bearing colon tumor. The plasma samples were extracted by precipitation method using acetonitrile with $0.1 \%$ formic acid. The chromatographic separation was achieved using mobile phase consisted of water and acetonitrile (57:43 v/v) pH 3 at the flow rate of $0.8 \mathrm{~mL} / \mathrm{min}$ in $\mathrm{C} 18$ column (internal diameter, $250 \times 4.6 \mathrm{~mm}$; pore size, $5 \mu \mathrm{m}$ ). The method was validated according to the bioanalytical guidelines defined by Food and Drug Administration (FDA) and European Medicine Agency (EMA). A regression $\left(R^{2}\right)$ value of 0.999 and 0.997 for IRT and SN38 suggested the good linearity in the range of $0.1-10 \mu \mathrm{g} / \mathrm{mL}$ and $5-500 \mathrm{ng} / \mathrm{mL}$, respectively. The calculated lower limit of quantification (LLOQ) and limit of detection (LOD) for IRT were 0.1 and $0.065 \mu \mathrm{g} / \mathrm{mL}$, respectively. However, for SN38, LLOQ and LOD were 5 and $2 \mathrm{ng} / \mathrm{mL}$, respectively. The intra-day and inter-day variations (coefficient of variance; $\% \mathrm{CV}$ ) observed during the validation were found to be within the set limit of $15 \%$. Both accuracy and percentage recovery analyzed and calculated from the quality control samples were in the between the defined range of $85-115 \%$. Plasma samples were found to be stable when stored at room temperature for $2 \mathrm{~h}$, after 2 freeze-thaw cycles and at $-80{ }^{\circ} \mathrm{C}$ for 2 months. The developed method was successfully applied to study the plasma elimination profile of IRT in NOD/SCID mice with tumor. The results from plasma concentration time profile and pharmacokinetic parameter analyzed suggested the rapid elimination of IRT and SN38 from the plasma of NOD/SCID mice.
\end{abstract}

Keywords: Irinotecan, SN38, HPLC, pharmacokinetic, validation, linearity, precision

\section{Introduction}

Irinotecan (IRT) is an anticancer agent derived from natural alkaloid camptothecin obtained from plant Camptotheca acuminate [1]. It is approved by Food and Drug Administration (FDA) as the first line treatment for metastatic colorectal cancer either alone or in combination with other chemotherapeutic agents (i.e., FOLFIRI: 5-fluorouracil, lecovorine, and irinotecan) or monoclonal antibodies (cetuximab, bevacizumab, and pantimumab) [2, 3]. Other than colorectal cancer, it is also broadly used in lymphoma, leukemia, breast, pancreatic, ovarian, brain, and small-cell lung cancer $[4,5]$. IRT exhibits its anticancer activity by inhibiting topoisomerase I and stabilizes the complex formed during the DNA replication resulting into the cell death [6]. IRT (7-ethyl-10-[4(1-piperidino)-1-piperidino]carbonyloxycamptothecin) acts as a prodrug and is converted by enzyme carboxylesterase (present in liver, intestine, plasma, saliva) into highly active metabolite SN38 (7-ethyl-10-hydroxycamptothecin; Figure 1) [7]. Compared to the parent drug (IRT), SN38 is $100-1000$ times more cytotoxic $[8,9]$.

IRT is a potent anticancer agent but has various gastrointestinal toxicities such as severe diarrhea, nausea, and vomiting [10]. It also causes reduction in the white and red blood cells count [11]. These side effects have significantly shifted the interest of researchers towards the development of novel drug

\footnotetext{
* Author for correspondence: ksingh1@uclan.ac.uk, profkksingh@gmail.com
}

delivery system for the effective and safe delivery of IRT. Different nanoparticles (NPs) including nanoliposomes [12, 13], poly(lactide-co-glycolic acid) (PLGA) NPs [14], solid lipid NPs [15], magnetic NPs [16], and human serum albuminbased NPs [17] of IRT have been developed and investigated for their anticancer potential in xenograft models. Onivyde, the liposomal formulation of IRT, was approved by FDA in October, 2015 for the treatment of metastatic pancreatic cancer following gemcitabine-based therapy $[18,19]$. Novel IRT conjugates including XMT-1001 and CRLX101 are in the clinical trials for the treatment of advance cancer [20,21].

The human tumor xenograft models are commonly used for preclinical assessment to screen the anticancer activity and establish pharmacokinetics (PK) of the existing drug or newly developed formulations [22, 23]. These models involve human cancer cell lines or tumor xenograft grown subcutaneously in immune-deficient host such as nude or nonobese diabetic/severe combined immune-deficient mice (NOD/SCID) and used for pharmacodynamic (PD) studies [24, 25]. The pharmacokinetic studies are usually preferred to be performed in these preclinical tumor xenograft models to explore the absorption, distribution, and elimination of the drug and new advanced formulations and determine PK/PD relationships before progressing to clinical trials. Also mouse models are more appealing than big animal models because of the ease-of-handling, low cost, and known genetic information [26]. The present research work aims towards the development and validation of

This is an open-access article distributed under the terms of the Creative Commons Attribution-NonCommercial 4.0 International License (https://creativecommons.org/licenses/by-nc/4.0/), which permits unrestricted use, distribution, and reproduction in any medium for non-commercial purposes, provided the original author and source are credited, a link to the CC License is provided, and changes - if any - are indicated. 


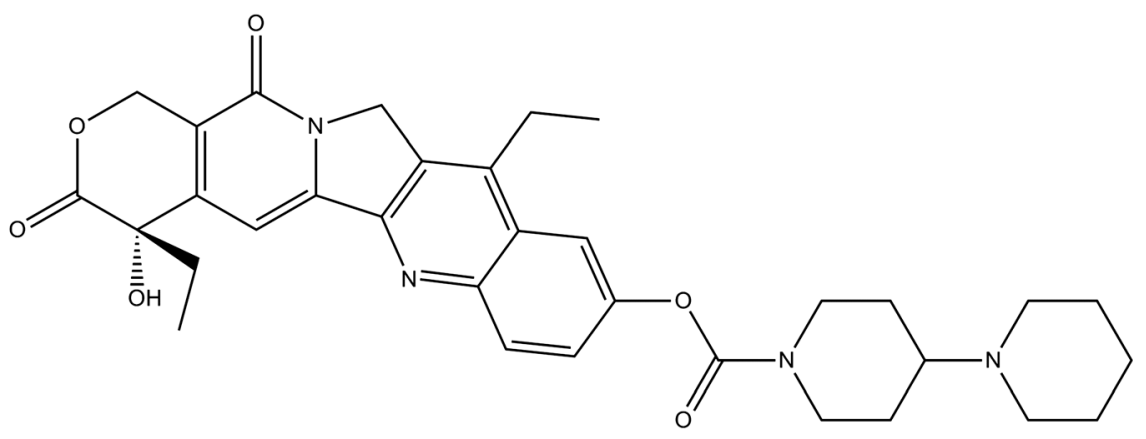

Irinotecan<smiles>CCc1c2c(nc3ccc(O)cc13)-c1cc3c(c(=O)n1C2)COC(=O)[C@@]3(O)CC</smiles>

SN38

Figure 1. Structure of irinotecan and SN38

analytical method for the determination of IRT and its metabolite SN38 in the plasma of NOD/SCID mice (human colon cancer xenograft model). There are several analytical techniques available such as high-performance liquid chromatography (HPLC) and liquid chromatography-mass spectroscopy (LC-MS) for the determination of IRT and its metabolite in biological samples $[27,28]$. However, the method developed by LC-MS is one of the expensive approaches and also includes the lengthy sample preparation time and extraction procedure [29]. Therefore, liquid chromatography was chosen over it for the method development of IRT and SN38. There are reports of quantification of IRT and SN38 by HPLC [30-32], but a very few studies have been published for the quantification of IRT in rats and mice plasma [33, 34]. However, to the best to our knowledge, there are no reports for analytical determination of IRT and SN-38 in tumor xenograft mice models. Therefore, to understand the plasma elimination profile of IRT and its active metabolite in the NOD/ SCID mice xenograft model, a new method was preferably established using reverse-phase HPLC coupled with fluorescence detector. The method was successfully developed, validated, and applied to measure the levels of IRT and SN38 in colon tumor bearing NOD/SCID mice plasma to establish the pharmacokinetics following intravenous administration of IRT at the dose of $20 \mathrm{mg} / \mathrm{kg}$.

\section{Materials and Method}

2.1 Reagents and Chemicals. Irinotecan hydrochloride trihydrate was obtained as a gift sample from Khandelwal Lab. Pvt. Ltd., Mumbai, India. SN38 and flurbiprofen were kindly provided by Piramal, Mumbai, India. Acetonitrile (ACN), ACN with $0.1 \%$ formic acid and orthophosphoric acid of HPLC grade, were procured from Merck Ltd., Mumbai, India. Milli-Q grade water purified by Milli-Q UV purification system (Millipore, Bedford, MA, USA) was used throughout the experiments. Dimethyl sulfoxide (DMSO) was purchased from Sigma, Mumbai, India.

\subsection{HPLC Method Development}

2.2.1 Instrument and Chromatographic Conditions. The high-performance liquid chromatographic system (JASCO LCNet II/ADC, Japan) consisting of gradient flow control pump, autosampler, column oven, and fluorescence detector was used for the method development. All the parameters of HPLC were controlled by ChromNav software. The chromatographic separation was achieved using BDS Hypersil C 18 column (internal diameter, $250 \times 4.6 \mathrm{~mm}$; pore size, $5 \mu \mathrm{m}$; Thermo scientific, USA) with column temperature of $40{ }^{\circ} \mathrm{C}$. The mobile phase consisted of water and ACN (57:43), pH adjusted to 3 with $0.5 \%$ orthophosphoric acid, and flow rate was kept at $0.8 \mathrm{~mL} / \mathrm{min}$. The mobile phase was filtered through $0.45 \mu \mathrm{m}$ filter and deaerated for $15 \mathrm{~min}$ by sonication before use. IRT was detected on fluorescence detector (FP-2020 plus, Japan) using excitation $\left(\lambda_{\mathrm{ex}}\right)$ and emission $\left(\lambda_{\mathrm{em}}\right)$ wavelength of $250 \mathrm{~nm}$ and $350 \mathrm{~nm}$, respectively. However, SN38 was detected at the $\lambda_{\text {ex }}$ of $370 \mathrm{~nm}$ and $\lambda_{\mathrm{em}}$ of $525 \mathrm{~nm}$. Flurbiprofen was used as internal standard (IS) for both analytes.

2.2.2 Preparation of Stock and Standard Working Solution. The stock solutions of IRT, SN38, and flurbiprofen were prepared in DMSO at the concentrations of $1000 \mu \mathrm{g} / \mathrm{mL}$ for IRT, $50 \mu \mathrm{g} / \mathrm{mL}$ for $\mathrm{SN} 38$, and $1000 \mu \mathrm{g} / \mathrm{mL}$ for flurbiprofen, respectively. These stock solutions were stored at $-80{ }^{\circ} \mathrm{C}$ till further used. Standard working solutions were prepared by serial dilution of stock solutions in water at the concentrations of 200, 100, 50, $20,10,5$, and $2 \mu \mathrm{g} / \mathrm{mL}$ for IRT and 1000, 500, 200, 100, 50, 20, and $10 \mathrm{ng} / \mathrm{mL}$ for SN38 (Table 1), respectively. For flurbiprofen, the working solution of $100 \mu \mathrm{g} / \mathrm{mL}$ was prepared in water. The aliquots of these working solution were further stored in polypropylene tubes at $-80{ }^{\circ} \mathrm{C}$. As presented in Table 1, the final calibration samples were prepared by spiking $5 \mu \mathrm{L}$ of respective standard working solution of IRT and $5 \mu \mathrm{L}$ of IS into $90 \mu \mathrm{L}$ of blank NOD/SCID mice plasma to obtain the final plasma concentrations of $0.1,0.25,0.5,1,2.5,5$, and $10 \mu \mathrm{g} / \mathrm{mL}$ of IRT and $5 \mu \mathrm{g} / \mathrm{mL}$ IS, whereas for the preparation of SN38 calibration curve, $90 \mu \mathrm{L}$ of plasma was spiked with respective $5 \mu \mathrm{L}$ of SN38 standard working solution and $5 \mu \mathrm{L}$ of IS to give the final 
Table 1. Preparation of working and final solutions

\begin{tabular}{|c|c|c|c|c|c|c|}
\hline \multirow{2}{*}{$\begin{array}{l}\text { Sr. } \\
\text { no. }\end{array}$} & \multicolumn{2}{|c|}{ IRT (stock solution: $1000 \mu \mathrm{g} / \mathrm{mL}$ ) } & \multicolumn{2}{|c|}{ SN38 (stock solution: $50 \mathrm{ng} / \mathrm{mL}$ ) } & \multicolumn{2}{|c|}{ Flurbiprofen $(1000 \mu \mathrm{g} / \mathrm{mL})$} \\
\hline & $\begin{array}{l}\text { Working solution } \\
\text { (WS) conc. }\end{array}$ & $\begin{array}{c}\text { Final conc. } \\
(5 \mu \mathrm{L} \text { of } \mathrm{WS}+90 \mu \mathrm{L} \text { of plasma) }\end{array}$ & $\begin{array}{l}\text { Working solution } \\
\text { (WS) conc. }\end{array}$ & $\begin{array}{c}\text { Final conc. } \\
(5 \mu \mathrm{L} \text { of } \mathrm{WS}+90 \mu \mathrm{L} \text { of plasma) }\end{array}$ & $\begin{array}{l}\text { Working solution } \\
\text { (WS) conc. }\end{array}$ & $\begin{array}{l}\text { Final } \\
\text { conc. }\end{array}$ \\
\hline 1 & 200 & 10 & 10,000 & 500 & 100 & 5 \\
\hline 2 & 100 & 5 & 5000 & 250 & & \\
\hline 3 & 50 & 2.5 & 2000 & 100 & & \\
\hline 4 & 20 & 1 & 1000 & 50 & & \\
\hline 5 & 10 & 0.5 & 500 & 25 & & \\
\hline 6 & 5 & 0.25 & 200 & 10 & & \\
\hline 7 & 2 & 0.1 & 100 & 5 & & \\
\hline
\end{tabular}

SN38 plasma concentrations of 5, 10, 20, 50, 100, 250, and $500 \mathrm{ng} / \mathrm{mL}$. Calibration samples were prepared freshly from the standard working solution every day during the validation process. Quality control (QC) samples were prepared in plasma at three concentrations (low, medium, and high) of 0.5, 2.5, and $5 \mu \mathrm{g} / \mathrm{mL}$ for IRT and 10,50 , and $250 \mathrm{ng} / \mathrm{mL}$ for SN38 from their respective working solutions.

2.2.3 Preparation of Plasma Samples. The plasma samples were thawed in ice bath, vortexed for $10 \mathrm{~s}$, and centrifuged at $10,000 \mathrm{rpm}$ for $10 \mathrm{~min}$ at $4{ }^{\circ} \mathrm{C}$. In order to extract IRT and SN38 from plasma samples, $1000 \mu \mathrm{L}$ of $\mathrm{ACN}$ with $0.1 \%$ formic acid was added to $95 \mu \mathrm{L}$ of plasma sample spiked with $5 \mu \mathrm{L}$ of IS. Mixture was allowed to stand for $5 \mathrm{~min}$, vortexed, and then centrifuged at 10,000 rpm for $10 \mathrm{~min}$. Next, $900 \mu \mathrm{L}$ of supernatant was transferred to new labeled polypropylene tubes and dried under nitrogen gas in Centrivap (Labconco, USA) at $40{ }^{\circ} \mathrm{C}$ for $1 \mathrm{~h}$. The dried samples were then reconstituted with $100 \mu \mathrm{L}$ of water-ACN $(80: 20 \mathrm{v} / \mathrm{v})$, vortexed, and again centrifuged at $10,000 \mathrm{rpm}$ for $10 \mathrm{~min}$. Supernatant was collected and diluted appropriately where required and collected in HPLC vials for the injection. To prevent the carry over effect, blank samples were run after every 3 samples during the analysis.

2.3 Method Validation. The developed analytical method was validated for specificity, linearity, sensitivity, precision, and accuracy according to the bio-analytical guidelines specified by US FDA and EMA $[35,36]$.

2.3.1 Selectivity. The selectivity of the method was assessed by analyzing six samples for each of the following: blank plasma, plasma samples spiked with IRT $(2.5 \mu \mathrm{g} / \mathrm{mL})$, and SN38 $(50 \mathrm{ng} / \mathrm{mL})$ separately. All samples were detected at $\lambda_{\mathrm{ex}}=250 \mathrm{~nm}$ and $\lambda_{\mathrm{em}}=350 \mathrm{~nm}$, and $\lambda_{\mathrm{ex}}=370 \mathrm{~nm}$ and $\lambda_{\mathrm{em}}=525 \mathrm{~nm}$ to determine any interference in detection of the two analytes with each other at these wavelengths. Plasma samples obtained after intravenous injection of IRT to NOD/SCID mice spiked with IS were also analyzed.

2.3.2 Calibration Curve. A calibration curve is the direct relationship between response and concentration of analyte and is used as a standard curve to determine the unknown concentration of analyte in plasma. The linearity of calibration curves was established and validated by conducting six runs of calibration samples during validation. The calibration curve in plasma for IRT was prepared using seven different concentrations of 0.1 , $0.25,0.5,1,2.5,5$, and $10 \mu \mathrm{g} / \mathrm{mL}$, respectively, whereas for SN38 concentrations of $5,10,20,50,100,250$, and $500 \mathrm{ng} / \mathrm{mL}$ were employed. The calibration curve was obtained by plotting the ratio of peak area of analyte (IRT, SN38) to the peak area of IS versus concentrations of analyte in mice plasma. The curve was further analyzed using linear least square regression to calculate slope, intercept, and regression coefficient $\left(R^{2}\right)$.

2.3.3 Limit of Detection and Limit of Quantification. The limit of detection (LOD) and lower limit of quantification (LLOQ) were determined at the signal to noise ratio of 3:1 and $10: 1$, respectively. The LLOQ is the concentration of analyte that is identifiable, reproducible, and can be back calculated with precision value (coefficient of variance; \% CV) not exceeding 20\% of the nominal concentration. LLOQ was established by analyzing five samples and determining the $\% \mathrm{CV}$.

2.3.4 Accuracy, Precision and Recovery. Accuracy represents the closeness of the mean test results obtained from the experiment to the actual concentration of analyte. The accuracy of the method was assessed by analyzing the quality control samples for IRT $(0.5,2.5,5 \mu \mathrm{g} / \mathrm{mL})$ and SN38 $(10,50,250 \mathrm{ng} / \mathrm{mL})$ for five times per calibration curve for six calibrations and deviation of mean from nominal value was measured. The precision of the analytical method describes the closeness of the results obtained when the procedure is applied multiple times for the analyte quantification. The intra-day variability of the method was calculated by comparing the results obtained from five replicates of QC concentration in one single analytical run on the same day. However, to measure inter-day variations, QC samples were run on different time and day.

The recovery of analyte can be defined as the ratio of added analyte concentration obtained from plasma to the true concentration of analyte in solvent. The extraction efficiency (\% recovery) of the developed method was calculated by running the extracted QC samples in five replicates, and the area was compared to the unextracted standard that represents the $100 \%$ recovery.

2.3.5 Dilution Test. Samples at higher concentration than the upper limit of quantitation need to be diluted prior to analysis. However, the dilution should not affect the reliability of quantitation. To establish dilution integrity of samples (dilution factor $10 \times)$, spiked QC sample $(5 \mu \mathrm{g} / \mathrm{mL})$ in plasma was diluted 10 times to give diluted QC sample. Five replicates of dilution QC were analyzed within an analytical run.

2.3.6 Stability. Stability of drug in plasma is a function of storage condition and should be evaluated during handling, short-term and long-term storage, and after freeze-thaw cycles [37]. To evaluate the stability of IRT and SN38 in plasma, QC samples were analyzed during sample storage and handling. Bench-top stability of samples was determined by analyzing the samples after $2 \mathrm{~h}$ at room temperature. The stability of the processed samples in autosampler was assessed by repeatedly analyzing these samples after 24 and $48 \mathrm{~h}$ of first injection. For freeze-thaw stability, the freshly prepared QC samples were processed and analyzed followed by the analysis of samples after two freeze-thaw cycles. Long-term stability of plasma samples was tested after storing the samples in $-80{ }^{\circ} \mathrm{C}$ for 2 months. The analyte is considered to be stable if the difference between the freshly prepared and stability samples does not deviate more than $15 \%$ from the nominal concentration [37].

\subsection{Application to Pharmacokinetic Study}

2.4.1 Animals. Female NOD/SCID mice with body weight of 18-22 g and 5-7 weeks of age were housed at Advanced Center for Treatment Research and Education in Cancer (ACTREC, Navi Mumbai, India). All experiments were carried out according to the protocol approved by the Institutional Animal Ethics Committee (IAEC) of ACTREC (proposal number: 26/2015). Mice were kept in a specific pathogen-free environment with 12:12 h light-dark cycle and were provided with unrestricted access to food and water ad libitum. 
2.4.2 Pharmacokinetic Study. The developed HPLC method was used to study the plasma concentration time profile in female NOD/SCID mice with colon tumor. Mice $(n=5)$ were injected intravenously with IRT at the dose of $20 \mathrm{mg} / \mathrm{kg}$ and blood was collected in ethylenediaminetetraacetic acid (EDTA) tubes by retro-orbital puncture after $0.25,0.50,1,2,4,6,8$, and $12 \mathrm{~h}$ of dose administration. Samples were centrifuged at 10,000 rpm for $10 \mathrm{~min}$ to separate plasma and stored at $-80{ }^{\circ} \mathrm{C}$ until analysis.

\section{Results and Discussion}

3.1 Method Optimization. Various preliminary experiments were carried out to develop the analytical method for the detection of IRT and SN38. For the extraction of analytes from plasma samples, ACN with $0.1 \%$ of formic acid was added in order to precipitate the proteins present in plasma. The extraction efficiency using ACN with $0.1 \%$ of formic acid was found to be $85 \%$, and no interfering peaks were observed. Moreover, other variables including temperature and time under the nitrogen steam were optimized as $40{ }^{\circ} \mathrm{C}$ and $1 \mathrm{~h}$, respectively, to assure the complete evaporation of organic solvent and thus good recovery of analytes form plasma. IRT is an ionizable compound and can be best separated at the mobile phase of $\mathrm{pH}$ less than 4 [38]. Therefore, to reduce the $\mathrm{pH}, 0.5 \%$ of orthophosphoric acid was added to the mobile phase. The good symmetry and shape of IRT peak with high resolution were achieved with the mobile phase consisting of water and acetonitrile $(57: 43 \mathrm{v} / \mathrm{v})$ with $\mathrm{pH}$ adjusted to 3 at the flow rate of $0.8 \mathrm{~mL} / \mathrm{min}$. This is contrary to previous report where low $\mathrm{pH}$ of mobile contributed to skewness and asymmetry in peak shape [39]. Fluorescence detection is very sensitive, and slight change in the excitation and emission wavelength was found to affect the response peak. Various excitation and emission wavelength were screened and peak with best symmetry, and resolution of IRT was identified at the $\lambda_{\text {ex }}$ of $250 \mathrm{~nm}$ and $\lambda_{\mathrm{em}}$ of 350 . However, the peak of SN38 specifically appeared at the $\lambda_{\mathrm{ex}}$ of $370 \mathrm{~nm}$ and $\lambda_{\mathrm{em}}$ of $525 \mathrm{~nm}$. Thus, the two analytes are detected at completely different excitation and emission wavelengths.
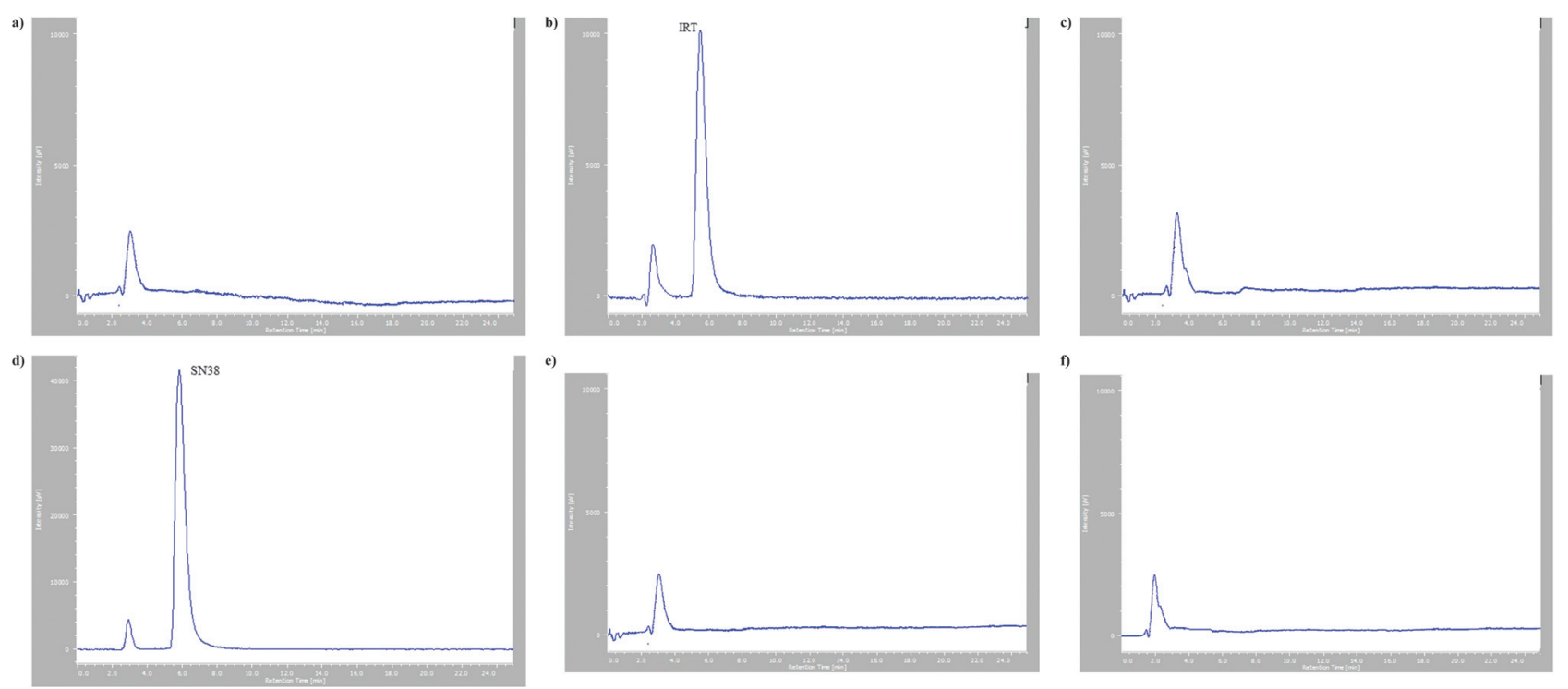

f)
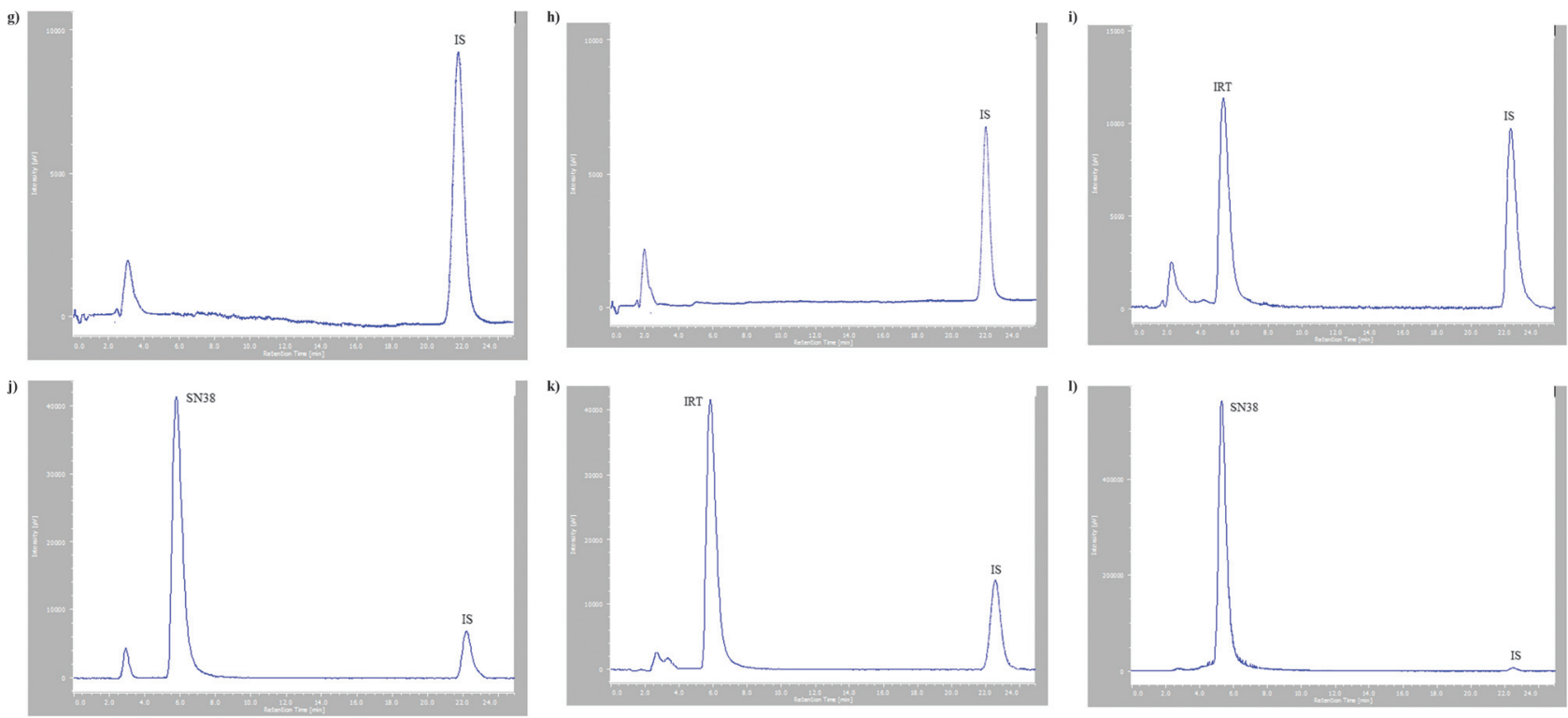

Figure 2. HPLC chromatogram of (a) blank plasma $\lambda_{\mathrm{ex}}=250 \mathrm{~nm}, \lambda_{\mathrm{em}}=350 \mathrm{~nm}$; (b) plasma spiked with IRT (2.5 $\left.\mu \mathrm{g} / \mathrm{mL}\right) \lambda_{\mathrm{ex}}=250 \mathrm{~nm}, \lambda_{\mathrm{em}}=$ $350 \mathrm{~nm}$; (c) blank plasma $\lambda_{\mathrm{ex}}=370 \mathrm{~nm}, \lambda_{\mathrm{em}}=525 \mathrm{~nm}$; (d) plasma spiked with SN38 (50 ng/mL) $\lambda_{\mathrm{ex}}=370 \mathrm{~nm}, \lambda_{\mathrm{em}}=525 \mathrm{~nm}$; (e) plasma spiked with IRT $(2.5 \mu \mathrm{g} / \mathrm{mL}) \lambda_{\mathrm{ex}}=370 \mathrm{~nm}, \lambda_{\mathrm{em}}=525 \mathrm{~nm}$; (f) plasma spiked with SN38 $(50 \mathrm{ng} / \mathrm{mL}) \lambda_{\mathrm{ex}}=250 \mathrm{~nm}, \lambda_{\mathrm{em}}=350 \mathrm{~nm}$; (g) plasma spiked with IS $(5 \mu \mathrm{g} / \mathrm{mL}) \lambda_{\mathrm{ex}}=250 \mathrm{~nm}, \lambda_{\mathrm{em}}=350 \mathrm{~nm}$; (h) plasma spiked with IS $(5 \mu \mathrm{g} / \mathrm{mL}) \lambda_{\mathrm{ex}}=370 \mathrm{~nm}, \lambda_{\mathrm{em}}=525 \mathrm{~nm}$; (i) plasma spiked with IRT (2.5 $\left.\mu \mathrm{g} / \mathrm{mL}\right)$ and IS $(5 \mu \mathrm{g} / \mathrm{mL}) \lambda_{\mathrm{ex}}=250 \mathrm{~nm}, \lambda_{\mathrm{em}}=350$; (j) plasma spiked with SN38 (50 ng/mL) $\lambda_{\mathrm{ex}}=370 \mathrm{~nm}, \lambda_{\mathrm{em}}=525 \mathrm{~nm}$; (k) IRT concentration in plasma samples of NOD/SCID mice after $15 \mathrm{~min}$ of i.v. administration of IRT at the dose of $20 \mathrm{mg} / \mathrm{kg}, \lambda_{\mathrm{ex}}=250 \mathrm{~nm}, \lambda_{\mathrm{em}}=350 \mathrm{~nm}$; (1) SN38 concentration in plasma samples of NOD/SCID mice after 15 min of i.v. administration of IRT at the dose of $20 \mathrm{mg} / \mathrm{kg}, \lambda_{\mathrm{ex}}=370 \mathrm{~nm}, \lambda_{\mathrm{em}}=525 \mathrm{~nm}$ 


\subsection{Method Validation}

3.2.1 Selectivity. The selectivity of the method is the ability to distinguish and quantify the analyte in the presence of other component in plasma samples. The chromatograms were as follows: (a) blank plasma $\lambda_{\mathrm{ex}}=250 \mathrm{~nm}, \lambda_{\mathrm{em}}=350 \mathrm{~nm}$; (b) plasma spiked with IRT $(2.5 \mu \mathrm{g} / \mathrm{mL}) \lambda_{\text {ex }}=250 \mathrm{~nm}, \lambda_{\text {em }}=350 \mathrm{~nm}$; (c) blank plasma $\lambda_{\mathrm{ex}}=370 \mathrm{~nm}, \lambda_{\mathrm{em}}=525 \mathrm{~nm}$; (d) plasma spiked with SN38 $(50 \mathrm{ng} / \mathrm{mL}) \lambda_{\mathrm{ex}}=370 \mathrm{~nm}, \lambda_{\mathrm{em}}=525 \mathrm{~nm}$; (e) plasma spiked with IRT $(2.5 \mu \mathrm{g} / \mathrm{mL}) \lambda_{\mathrm{ex}}=370 \mathrm{~nm}, \lambda_{\mathrm{em}}=525 \mathrm{~nm}$; (f) plasma spiked with $\mathrm{SN} 38(50 \mathrm{ng} / \mathrm{mL}) \lambda_{\mathrm{ex}}=250 \mathrm{~nm}, \lambda_{\mathrm{em}}=$ $350 \mathrm{~nm}$; (g) plasma spiked with IS $(5 \mu \mathrm{g} / \mathrm{mL}) \lambda_{\mathrm{ex}}=250 \mathrm{~nm}$, $\lambda_{\mathrm{em}}=350 \mathrm{~nm}$; (h) plasma spiked with IS $(5 \mu \mathrm{g} / \mathrm{mL}) \lambda_{\mathrm{ex}}=$ $370 \mathrm{~nm}, \lambda_{\mathrm{em}}=525 \mathrm{~nm}$; (i) plasma spiked with IRT $(2.5 \mu \mathrm{g} / \mathrm{mL})$ and IS $(5 \mu \mathrm{g} / \mathrm{mL}) \lambda_{\mathrm{ex}}=250 \mathrm{~nm}, \lambda_{\mathrm{em}}=350$; (j) plasma spiked with SN38 $(50 \mathrm{ng} / \mathrm{mL}) \lambda_{\mathrm{ex}}=370 \mathrm{~nm}, \lambda_{\mathrm{em}}=525 \mathrm{~nm}$; (k) IRT concentration in plasma samples of NOD/SCID mice after $15 \mathrm{~min}$ of i.v. administration of IRT at the dose of $20 \mathrm{mg} / \mathrm{kg}$, $\lambda_{\text {ex }}=250 \mathrm{~nm}, \lambda_{\mathrm{em}}=350 \mathrm{~nm}$; and (l) SN38 concentration in plasma samples of NOD/SCID mice after 15 min of i.v. administration of IRT at the dose of $20 \mathrm{mg} / \mathrm{kg}, \lambda_{\mathrm{ex}}=370 \mathrm{~nm}, \lambda_{\mathrm{em}}=$ $525 \mathrm{~nm}$ (Figure 2). There was no interference observed in the determination of IRT and SN38 from plasma component. The detection of peaks of IRT and SN38 was wavelength specific. IRT was detected at $\lambda_{\mathrm{ex}}=250 \mathrm{~nm}$ and $\lambda_{\mathrm{em}}=350 \mathrm{~nm}$ while SN38 was detected at $\lambda_{\mathrm{ex}}=370 \mathrm{~nm}$ and $\lambda_{\mathrm{em}}=525 \mathrm{~nm}$. However, no peaks were observed for IRT at $\lambda_{\mathrm{ex}}=370 \mathrm{~nm}$ and $\lambda_{\mathrm{em}}=$ $525 \mathrm{~nm}$ and SN38 at $\lambda_{\mathrm{ex}}=250 \mathrm{~nm}$ and $\lambda_{\mathrm{em}}=350 \mathrm{~nm}$, respectively (Figure 2). Flurbiprofen was selected as internal standard as it was detected at both the excitation and emission wavelengths and could thus act as internal standard for both the analytes. The retention times of IRT and SN38 were found to be $5.8 \pm 0.3$ and $6.3 \pm 0.25 \mathrm{~min}$, respectively, while the internal standard eluted at $22.3 \pm 0.4 \mathrm{~min}$.

3.2.2 Calibration Curve, LLOQ and LOD. A good linearity of the curve was observed in the range of $0.1-10 \mu \mathrm{g} / \mathrm{mL}$ for IRT and 5-500 ng/mL for SN38 as seen in Figure 3a and b, respectively. The parameters obtained from linear regression are given in Table 2 . The calculated regression equation for IRT and SN38 was $Y=1.571 x-0.078$ and $Y=0.201 x+$ 25.49 , respectively (Table 2$)$. The regression coefficient $\left(R^{2}\right)$ value of 0.999 for IRT and 0.997 for SN38 from calibration curve presents the goodness of fit of the calibration curve. The LLOQ and LOD for IRT were found to be $0.1 \mu \mathrm{g} / \mathrm{mL}$ and $0.065 \mu \mathrm{g} / \mathrm{mL}$, respectively, whereas for SN38 LLOQ was $5 \mathrm{ng} / \mathrm{mL}$ and LOD was $2 \mathrm{ng} / \mathrm{mL}$, respectively.

3.2.3 Accuracy, Precision, and Recovery. The intra-day and inter-day precisions for both IRT and SN38 were found within in the prescribed limits of \% CV less than 15 (Tables 3 and 4). The results from accuracy studies showed that accuracy values falls in between the range of $85 \%-115 \%$ and the developed method was accurate to determine the amount of IRT and SN38 in plasma. The percentage recovery from plasma samples at QC concentrations were $91.14 \%, 89.23 \%$, and $90.48 \%$ for IRT and $87.19 \%, 93.91 \%$, and $97.41 \%$, respectively, for SN38 (Table 5). The recovery of IS was found to be above $95 \%$.

3.2.4 Dilution Test. Dilution integrity was validated, and the final concentration was back calculated by applying the dilution factor and was found to be not deviating from the nominal concentration by more than $15 \%$. Thus, dilution of sample did not impact precision and accuracy of the method.

3.2.5 Stability. The analyte in plasma showed good stability after being stored for $2 \mathrm{~h}$ at room temperature and $48 \mathrm{~h}$ in autosampler when reconstituted in water during bench-top stability study [40]. The \% CV of IRT and SN38 after extraction from these plasma samples was found to be $12.2 \%$ and $10.9 \%$, respectively (i.e., $<15 \%$ ). The IRT and SN38 also a)

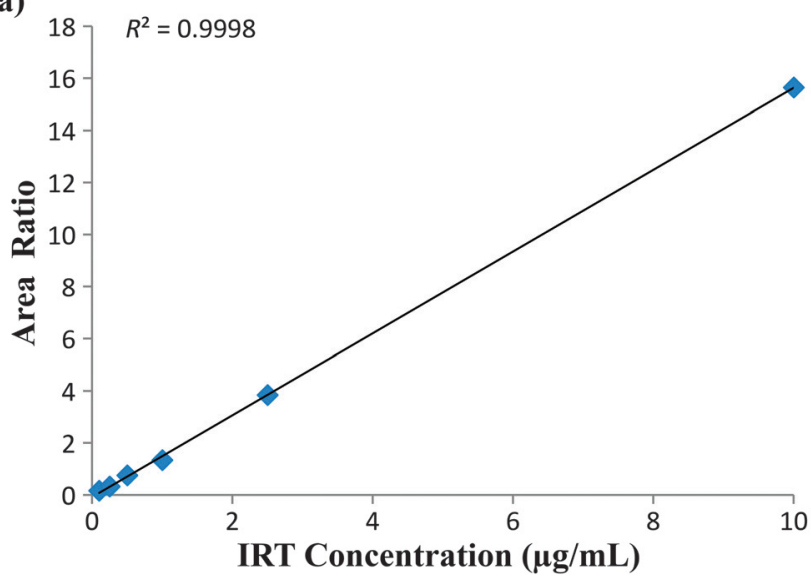

b)

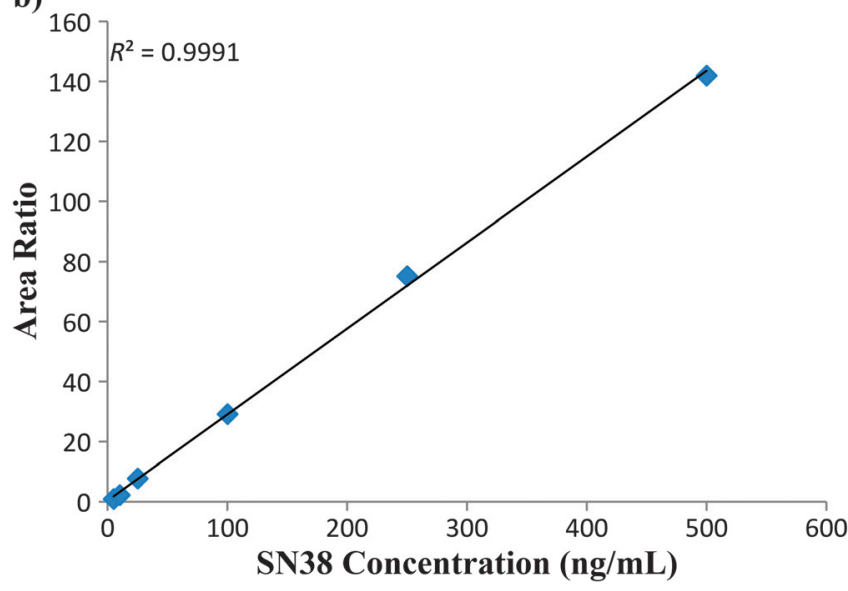

Figure 3. Calibration curves of IRT and SN38 in NOD/SCID ice plasma

Table 2. Parameters of linear regression analysis

\begin{tabular}{lcc}
\hline & IRT & $\mathrm{SN} 38$ \\
\hline Linearity range & $0.1-10 \mu \mathrm{g} / \mathrm{mL}$ & $5-500 \mathrm{ng} / \mathrm{mL}$ \\
Regression equation & $Y=1.571 x-0.078$ & $Y=0.201 x+25.49$ \\
Regression coefficient $\left(R^{2}\right)$ & 0.999 & 0.997 \\
Slope & 1.571 & 0.201 \\
Intercept & 0.078 & 25.49 \\
\hline
\end{tabular}

Table 3. Intra-day and Inter-day precision and accuracy of IRT (QC samples)

\begin{tabular}{|c|c|c|c|c|c|c|}
\hline \multirow{2}{*}{$\begin{array}{l}\text { IRT conc. } \\
\text { (ng/mL) }\end{array}$} & \multicolumn{3}{|c|}{ Intra-day } & \multicolumn{3}{|c|}{ Inter-day } \\
\hline & Mean \pm SD & $\begin{array}{l}\% \\
\mathrm{CV}\end{array}$ & $\begin{array}{c}\% \\
\text { Accuracy }\end{array}$ & $\overline{\text { Mean } \pm \text { SD }}$ & $\begin{array}{l}\% \\
\mathrm{CV}\end{array}$ & $\begin{array}{c}\% \\
\text { Accuracy }\end{array}$ \\
\hline 0.5 & $0.48 \pm 0.06$ & 14.19 & 95.67 & $0.52 \pm 0.03$ & 7.42 & 104.1 \\
\hline 2.5 & $2.17 \pm 0.23$ & 10.74 & 86.82 & $2.07 \pm 0.11$ & 5.40 & 83.02 \\
\hline 5 & $4.80 \pm 0.31$ & 6.56 & 96.10 & $5.11 \pm 0.07$ & 1.52 & 102.35 \\
\hline
\end{tabular}

Table 4. Intra-day and inter-day precision and accuracy of SN38 (QC samples)

\begin{tabular}{|c|c|c|c|c|c|c|}
\hline \multirow{2}{*}{$\begin{array}{l}\text { SN38 conc. } \\
\text { (ng/mL) }\end{array}$} & \multicolumn{3}{|c|}{ Intra-day } & \multicolumn{3}{|c|}{ Inter-day } \\
\hline & Mean $\pm \mathrm{SD}$ & $\begin{array}{l}\% \\
\mathrm{CV}\end{array}$ & $\begin{array}{c}\% \\
\text { Accuracy }\end{array}$ & Mean \pm SD & $\begin{array}{c}\% \\
\mathrm{CV}\end{array}$ & $\begin{array}{c}\% \\
\text { Accuracy }\end{array}$ \\
\hline 10 & $9.33 \pm 1.33$ & 14.30 & 93.36 & $10.49 \pm 0.36$ & 3.51 & 104.98 \\
\hline 50 & $54.14 \pm 7.25$ & 13.39 & 108.29 & $49.49 \pm 1.51$ & 3.06 & 98.99 \\
\hline 250 & $242.98 \pm 13.5$ & 5.55 & 97.19 & $242.98 \pm 4.16$ & 1.71 & 97.19 \\
\hline
\end{tabular}

Table 5. Percentage recovery of IRT and SN38 from QC samples

\begin{tabular}{lccr}
\hline IRT conc. $(\mu \mathrm{g} / \mathrm{mL})$ & \% Recovery & SN38 $(\mathrm{ng} / \mathrm{mL})$ & \% Recovery \\
\hline 0.5 & $91.14 \pm 3.26$ & 10 & $87.19 \pm 8.13$ \\
2.5 & $89.23 \pm 5.64$ & 50 & $93.91 \pm 4.82$ \\
5 & $90.48 \pm 7.60$ & 250 & $97.41 \pm 5.37$ \\
IS $(5 \mu \mathrm{g} / \mathrm{mL})$ & $95.31 \pm 3.29$ & IS $(5 \mu \mathrm{g} / \mathrm{mL})$ & $95.31 \pm 3.29$ \\
\hline
\end{tabular}


remained stable in the plasma after 2 freeze-thaw cycles [41]. The \% CV for IRT and SN38 after 2 freeze-thaw cycles was $9.0 \%$ and $10.2 \%$, respectively. After long-term storage of plasma samples at $-80{ }^{\circ} \mathrm{C}$ for 2 months, analytes showed $\%$ $\mathrm{CV}$ with in limit of $15 \%$. This in agreement with previous literature reports $[41,42]$.

3.3 Pharmacokinetic Study. The plasma elimination profile of IRT was studied in NOD/SCID mice bearing colon tumor after intravenous administration of IRT at the dose of $20 \mathrm{mg} / \mathrm{kg}$. Plasma concentration at the given time points were calculated and plotted against time. Data on plasma drug concentration over time were analyzed using the noncompartmental analysis with the software WinNonLine Professional (version 5.0.1, Pharsight Corporation, CA). The pharmacokinetic parameters calculated for IRT and SN38 including $C_{\max }, t_{1 / 2}$, area under curve (AUC), volume of distribution $\left(V_{\mathrm{d}}\right)$, and clearance $(\mathrm{Cl})$ were calculated and are given in Table 6. As seen from Figure 4a, a sharp decline in the plasma concentration of IRT was observed with time and IRT was found to be completely eliminated from plasma within $12 \mathrm{~h}$ of dose administration. The results are in compliance with the earlier studies where the fast elimination of free IRT was observed in xenograft models [43, 44]. The concentration of SN38 was found to increase initially in first 30 minutes followed by the elimination up to $24 \mathrm{~h}$ (Figure $4 \mathrm{~b}$ ). The initial rise in concentration of SN38 can be explained by the biological conversion of IRT into its active metabolite SN38 [45]. The $t_{1 / 2}$ value of $2.14 \mathrm{~h}$ and $1.68 \mathrm{~h}$ for IRT and

Table 6. Parameter obtained from plasma concentration versus time plot after intravenous administration of IRT at dose of $20 \mathrm{mg} / \mathrm{kg}$

\begin{tabular}{lccc}
\hline Sr. no. & Parameters & IRT & SN38 \\
\hline 1 & $C_{\max }$ & $8.615 \pm 1.20 \mu \mathrm{g} / \mathrm{mL}$ & $1760.84 \pm 210.21 \mathrm{ng} / \mathrm{mL}$ \\
2 & $t_{1 / 2}$ & $2.14 \mathrm{~h} \pm 0.12$ & $1.68 \pm 0.09 \mathrm{~h}$ \\
3 & $\mathrm{AUC}$ & $13.451 \pm 1.37 \mathrm{~h} * \mu \mathrm{g} / \mathrm{mL}$ & $3850.88 \pm 920.1 \mathrm{~h} * \mathrm{ng} / \mathrm{mL}$ \\
4 & $V_{\mathrm{d}}$ & $4.518 \pm 0.213 \mathrm{~L} / \mathrm{kg}$ & - \\
5 & $\mathrm{Cl}$ & $1.462 \pm 0.012 \mathrm{~L} / \mathrm{h} / \mathrm{kg}$ & - \\
\hline
\end{tabular}
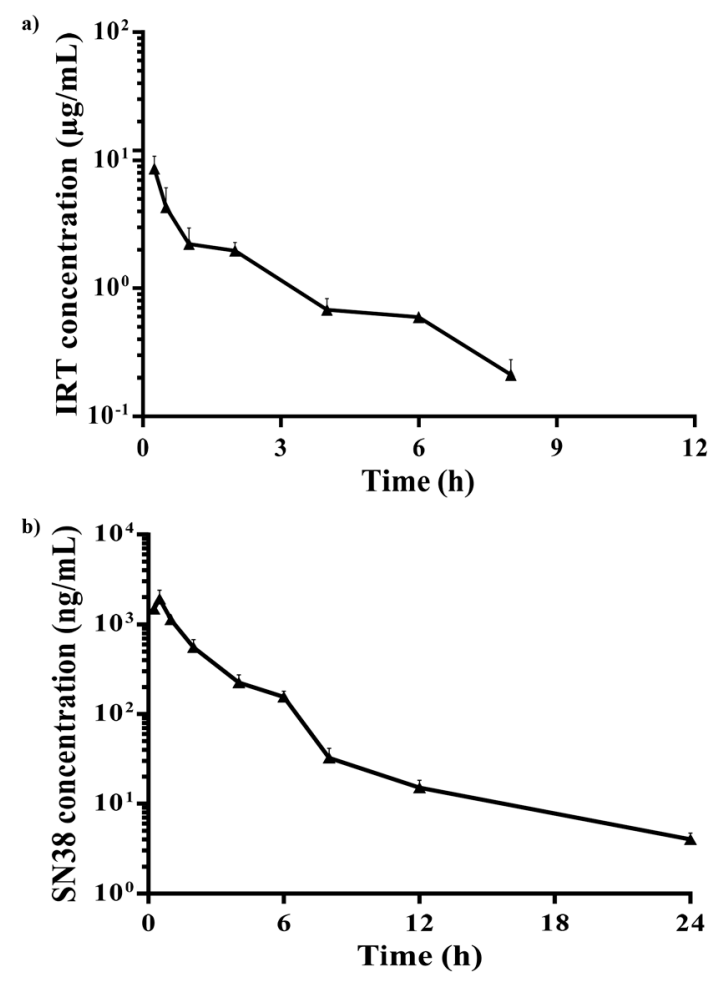

Figure 4. Plasma elimination profile of (a) IRT and (b) SN38 after intravenous administration of IRT at the dose of $20 \mathrm{mg} / \mathrm{kg}$ in NOD/SCID mice
SN38, respectively, again suggested the rapid elimination of IRT and its metabolite from plasma. The AUC of IRT and SN38 was found to be $13.451 \mathrm{~h}^{*} \mu \mathrm{g} / \mathrm{mL}$ and $3850.88 \mathrm{~h}^{*} \mathrm{ng} / \mathrm{mL}$, respectively. The results indicated short half life, rapid elimination, and low bioavailability of IRT in NOD/SCID mice.

\section{Conclusion}

IRT is an extensively used drug in the treatment of various carcinomas but have many side effects. Alternatively, novel nanoparticulate formulations have been developed for the safe and targeted delivery of drug to the tumor site. Human tumor xenograft models are most common animal models used for preclinical assessment and evaluating pharmacokinetic, biodistribution, and anticancer activity of existing or novel drug delivery systems. To study the pharmacokinetic profile of IRT in the plasma of NOD/SCID mice bearing colon tumor, a new, simple, and sensitive method using HPLC with fluorescence detection has been developed to quantify IRT and its active metabolite SN38. The method was successfully developed and validated in NOD/SCID mice plasma according to the bioanalytical guidelines by FDA. The developed method has been effectively applied to study the plasma elimination profile of IRT and SN38 after intravenous administration of IRT at the dose of $20 \mathrm{mg} / \mathrm{kg}$ and determine pharmacokinetic parameters in NOD/SCID mice. This method can be used in future PK/PD modeling studies for IRT and its novel formulations.

\section{Conflict of Interest}

There are no conflicts of interest.

Acknowledgment. Author Neetika Taneja (UGC-BSR Senior Research Fellow) is thankful to the University Grant Commission (UGC, Delhi) for providing the financial support to the project. We are also thankful to Advance Center for Training Research and Education in Cancer (ACTREC, Kharghar, Mumbai) for providing the animals and housing facility for the experiment.

\section{References}

1. Nirmala, M. J.; Samundeeswari, A.; Sankar, P. D. Research in Plant Biology 2011, 1 .

2. Van Cutsem, E.; Köhne, C.-H.; Láng, I.; Folprecht, G.; Nowacki, M. P.; Cascinu, S.; Shchepotin, I.; Maurel, J.; Cunningham, D.; Tejpar, S. J. Clin. Oncol. 2011, 29, 2011-2019.

3. Douillard, J.; Cunningham, D.; Roth, A.; Navarro, M.; James, R.; Karasek, P.; Jandik, P.; Iveson, T.; Carmichael, J.; Alakl, M. The Lancet 2000, 355, 1041-1047.

4. Rosen, L. S. Oncology 1998, 12, 103-109.

5. Vredenburgh, J. J.; Desjardins, A.; Herndon, J. E.; Marcello, J.; Reardon, D. A.; Quinn, J. A.; Rich, J. N.; Sathornsumetee, S.; Gururangan, S.; Sampson, J. J. Clin. Oncol. 2007, 25, 4722-4729.

6. Liu, L. F.; Desai, S. D.; LI, T. K.; Mao, Y.; Sun, M.; SIM, S. P. Ann. N. Y. Acad. Sci. 2000, 922, 1-10.

7. Rivory, L. P.; Bowles, M. R.; Robert, J.; Pond, S. M. Biochem. Pharmacol. 1996, 52, 1103-1111.

8. Dodds, H. M.; Haaz, M.-C.; Riou, J.-F.; Robert, J.; Rivory, L. P. J. Pharmacol. Exp. 1998, 286, 578-583.

9. Humerickhouse, R.; Lohrbach, K.; Li, L.; Bosron, W. F.; Dolan, M. E. Cancer Res. 2000, 60, 1189-1192.

10. Trifan, O. C.; Durham, W. F; Salazar, V. S.; Horton, J.; Levine, B. D. Zweifel, B. S.; Davis, T. W.; Masferrer, J. L. Cancer Res. 2002, 62, 5778-5784.

11. Cunningham, D.; Pyrhönen, S.; James, R. D.; Punt, C. J.; Hickish, T. F.; Heikkila, R.; Johannesen, T. B.; Starkhammar, H.; Topham, C. A.; Awad, L. The Lancet 1998, 352, 1413-1418.

12. Drummond, D. C.; Noble, C. O.; Guo, Z.; Hong, K.; Park, J. W.; Kirpotin, D. B. Cancer Res. 2006, 66, 3271-3277.

13. Ramsay, E. C.; Anantha, M.; Zastre, J.; Meijs, M.; Zonderhuis, J.; Strutt, D.; Webb, M. S.; Waterhouse, D.; Bally, M. B. Clin. Cancer Res. 2008, 14, 1208-1217.

14. Paruchuri, R.; Trivedi, S.; Joshi, S. V.; Pavuluri, G.; Senthil Kumar, M. Int. J. Pharm. Chem. Biol. Sci. 2012, 2, 1-10.

15. Martins, S.; Tho, I.; Reimold, I.; Fricker, G.; Souto, E.; Ferreira, D.; Brandl, M. Int. J. Pharm. 2012, 439, 49-62.

16. Tamyurek, E.; Maltas, E.; Bas, S. Z.; Ozmen, M.; Yildiz, S. Int. J. Biol. Macromol. 2015, 73, 76-83. 
17. Taneja, N.; Singh, K. K. Int. J. Pharm. 2018, 536, 82-94

18. Passero Jr, F. C.; Grapsa, D.; Syrigos, K. N.; Saif, M. W. Expert Rev. 2016, 16, 697-703.

19. DiGiulio, S. Oncology Times 2015

20. Tian, X.; Nguyen, M.; Foote, H. P.; Caster, J. M.; Roche, K. C.; Peters, C. G.; Wu, P.; Jayaraman, L.; Garmey, E. G.; Tepper, J. E. Cancer Res. 2017, $77,112-122$.

21. Walsh, M. D.; Hanna, S. K.; Sen, J.; Rawal, S.; Cabral, C. B.; Yurkovetskiy, A. V.; Fram, R. J.; Lowinger, T. B.; Zamboni, W. C. Clin. Cancer Res. 2012, 18, 2591-2602.

22. Kerbel, R. S. Cancer Biol. Ther. 2003, 2, 133-138.

23. Jung, J. Toxicological Res. 2014, 30, 1-5.

24. Voskoglou-Nomikos, T.; Pater, J. L.; Seymour, L. Clin. Cancer Res. 2003, 9, 4227-4239.

25. Belizário, J. E. Open Immunol. J. 2009, 2, 79-85.

26. Cheon, D.-J.; Orsulic, S. Annu. Rev. Pathol.: Mech. Dis. 2011, 6, 95-119.

27. Tariq, M.; Negi, L.; Talegaonkar, S.; Ahmad, F.; Iqbal, Z.; Khan, A. Indian J. Pharm. Sci. 2015, 77, 14.

28. Marangon, E.; Posocco, B.; Mazzega, E.; Toffoli, G. PloS One 2015, 10, $\mathrm{e} 0118194$.

29. Qi, P.; Zeng, T.; Wen, Z.; Liang, X.; Zhang, X. Food Chem. 2011, 125, $1462-1467$.

30. Chen, X.; Peer, C.J.; Alfaro, R.; Tian, T.; Spencer, S. D.; Figg, W. D. J. Pharm. Biomed. Anal. 2012, 62, 140-148.

31. de Bruijn, P.; Verweij, J.; Loos, W. J.; Nooter, K.; Stoter, G.; Sparreboom, A. J. Chromatogr. B: Biomed. Sci. Appl. 1997, 698, 277-285.

32. Poujol, S.; Pinguet, F.; Malosse, F.; Astre, C.; Ychou, M.; Culine, S.; Bressolle, F. Clin. Chem. 2003, 49, 1900-1908.
33. Bansal, T.; Awasthi, A.; Jaggi, M.; Khar, R. K.; Talegaonkar, S. Talanta 2008, 76, 1015-1021.

34. Chollet, D. F.; Goumaz, L.; Renard, A.; Montay, G.; Vernillet, L.; Arnera, V.; Mazzo, D. J. J. Chromatogr. B: Biomed. Sci. Appl. 1998, 718, 163-175.

35. US Food and Drug Administration, FDA guidance for industry: bioanalytical method validation. US Department of Health and Human Services, Food and Drug Administration, Center for Drug Evaluation and Research: Rockville, MD, 2001.

36. Agency, E. M. Guideline on bioanalytical method validation. Committee for Medicinal Products for Human Use (CHMP), 2011.

37. Al-Dgither, S.; Alvi, S. N.; Hammami, M. M. J. Pharm. Biomed. Anal. 2006, 41, 251-255.

38. Balaram, V. M.; Rao, J. V.; Ganesh, G. R. S. S.; Krishna, T. B. J. Chem. 2007, 4, 128-136

39. Hu, Z.-P.; Yang, X.-X.; Chen, X.; Chan, E.; Duan, W.; Zhou, S.-F. J. Chromatogr. B 2007, 850, 575-580.

40. Sano, K.; Yoshikawa, M.; Hayasaka, S.; Satake, K.; Ikegami, Y.; Yoshida, H.; Ishikawa, T.; Sawada, S.; Tanabe, S. J. Chromatogr. B 2003, 795, 25-34.

41. Rivory, L. P.; Robert, J. J. Chromatogr. B: Biomed. Sci. Appl. 1994, 661, $133-141$.

42. Sumiyoshi, H.; Fujiwara, Y.; Ohune, T.; Yamaoka, N.; Tamura, K.; Yamakido, M. J. Chromatogr. B: Biomed. Sci. Appl. 1995, 670, 309-316.

43. Messerer, C. L.; Ramsay, E.C.; Waterhouse, D.; Ng, R.; Simms, E.-M.; Harasym, N.; Tardi, P.; Mayer, L. D.; Bally, M. B. Clin. Cancer Res. 2004, 10, 6638-6649.

44. Shaikh, I. M.; Tan, K.-B.; Chaudhury, A.; Liu, Y.; Tan, B.-J.; Tan, B. M.; Chiu, G. N. J. Control. Release 2013, 172, 852-861.

45. Wu, M. H.; Yan, B.; Humerickhouse, R.; Dolan, M. E. Clin. Cancer Res. 2002, 8, 2696-2700 